\title{
Editorial: Alternative Therapeutics Against Antimicrobial-Resistant Pathogens
}

\author{
Rebecca Thombre ${ }^{1,2 \star}$, Kamlesh Jangid ${ }^{3}$, Ravi Shukla $^{4}$ and Noton Kumar Dutta ${ }^{5}$ \\ ${ }^{1}$ Department of Biotechnology, Modern College of Arts, Science and Commerce, Pune, India, ${ }^{2}$ School of Physical Sciences, \\ University of Kent, Canterbury, United Kingdom, ${ }^{3}$ National Centre for Microbial Resource, National Centre for Cell Science, \\ Savitribai Phule Pune University Campus, Pune, India, ${ }^{4}$ NanoBiotechnology Research Laboratory, RMIT University, \\ Melbourne, VIC, Australia, ${ }^{5}$ Center for Tuberculosis Research, Department of Medicine, Johns Hopkins University School of \\ Medicine, Baltimore, MD, United States
}

Keywords: antimicrobial resistance (AMR), multidrug-resistance (MDR), nanomaterials, nanoparticles, plant based compounds, antimicrobial agents, alternative therapy, novel compounds

\section{Editorial on the Research Topic}

\section{Alternative Therapeutics Against Antimicrobial-Resistant Pathogens}

OPEN ACCESS

Edited by:

Henrietta Venter,

University of South Australia, Australia

Reviewed by:

Jianhua Wang,

Feed Research Institute (CAS), China

*Correspondence:

Rebecca Thombre rebecca.thombre@gmail.com

Specialty section

This article was submitted to Antimicrobials, Resistance and Chemotherapy

a section of the journal

Frontiers in Microbiology

Received: 26 July 2019 Accepted: 05 September 2019 Published: 19 September 2019

Citation:

Thombre R, Jangid K, Shukla $R$ and Dutta NK (2019) Editorial: Alternative Therapeutics Against Antimicrobial-Resistant Pathogens. Front. Microbiol. 10:2173. doi: 10.3389/fmicb.2019.02173
Antimicrobial resistance (AMR) has emerged as one of the greatest global challenge to public health in the twenty-first century. The use of antibiotics is associated with the serendipitous discovery of Penicillin by Sir Alexander Fleming in 1928 (Fleming, 1929). However, Emmerich and Löw had demonstrated the first application of the antibiotic "Pyocyanase" in hospital in 1899. The golden era of antibiotic was ushered between 1950s and 1970s which was marked by rapid developments in discoveries of many classes and types of antibiotics (Emmerich and Löw, 1899). The increased use and abuse of antibiotics caused the emergence of multidrug resistant bacteria that caused hard-to-treat infections (Aminov, 2010). It is imperative to search alternative therapeutics and strategies to combat AMR and diminish the exacerbated use of antibiotics. In this special issue, we present 26 articles that highlight the use of novel peptides, phage-based therapies, nanomedicine, contemporary and alternative medicines, plant (herbal), and bacteria based antimicrobials as potential alternatives to combat multidrug resistant (MDR) bacteria. The articles are categorized in different groups, including (i) Antimicrobial nanoparticles against drug resistant bacteria, (ii) Bacteriophages: A promising approach to fight MDR, (iii) Anti biofilm agents, (iv) Antimicrobial peptides, (v) Efflux pump inhibitors, and (vi) Host /Pathogen directed therapies.

A variety of repurposing FDA-approved drugs (Sharma et al.) that are employed in the management of pathological conditions of non-infectious etiology have been shown to exhibit broad spectrum antimicrobial activity in vitro and in vivo. Such compounds including marine eukaryotes like seaweeds (Karthick and Mohanraju), phytochemicals (Kim et al.; Lu et al.), antimicrobial peptides and proteins (Kumar et al.), termed "non-antibiotics" (Dutta et al., 2007; Mazumdar et al., 2009, 2010), possess antibacterial properties, acting through mechanisms different from those of existing drugs, by enhancement of combination-therapy effective (Pachon-Ibanez et al.; Shriram et al.), reversal of drug resistance (Guo et al.; Patwardhan et al.) or re-sensitizing activities (Dutta et al., 2014; Shriram et al.), inhibition of biofilm formation (Guo et al.; Karumathil et al.; Kaur et al.; Khalifa et al.; Kim et al.; Lu et al.; Punjabi et al.), as well as by induction and control of efflux pumps (Dutta et al., 2010; Baptista et al.; Karumathil et al.; Lu et al.; Shriram et al.). 
This broad group of antimicrobial agents has two subgroups, each with distinctly different adjunct activities, either pathogen-directed or host directed. The first group is that of the antimicrobial non-antibiotics-drugs that have direct antimicrobial activity and the proposed path for compounds targeting microbial factors. The second group can generally be classified into two categories: those that enhance the antimicrobial activity of the host immune system, and those which dampen the inflammatory response preventing tissue damage (Karumathil et al.; Singh and Subbian). Hostdirected therapies are attractive options as they are not prone to the resistance associated with antibiotics (Dutta et al., 2016; Frank et al., 2019). Currently, the following HDT agents are being evaluated in phase 2 clinical trials as adjuncts to rifabutin-modified standard therapy in adults with drug-sensitive, smear-positive pulmonary TB: (1) the mammalian target of rapamycin (mTOR) inhibitor, everolimus (0.5 mg), (2) auranofin (6 mg), (3) vitamin D3, and (4) the phosphodiesterase-4 (PDE4) inhibitor, CC-11050 (ClinicalTrials.gov Identifier: NCT02968927). A randomized clinical trial, Statins as Adjunctive Therapy for TB (StAT-TB), is currently underway to determine if pravastatin adjunctive therapy shortens the median time to sputum-culture negativity and improves lung function outcomes among HIV-infected and uninfected patients with drug-susceptible pulmonary TB (NCT03456102).

In summary, these articles cover a vast expanse of research findings based on emerging trends in combatting antimicrobial resistance using traditional and natural antimicrobials, plant and microbial derivatives and nanomaterials. Currently, AMR is a

\section{REFERENCES}

Aminov, R. I. (2010). A brief history of the antibiotic era: lessons learned and challenges for the future. Front. Microbiol. 1:134. doi: 10.3389/fmicb.2010.00134

Buckner, M., Ciusa, M. L., and Piddock, L. (2018). Strategies to combat antimicrobial resistance: anti-plasmid and plasmid curing. FEMS Microbiol. Rev. 42, 781-804. doi: 10.1093/femsre/fuy031

Dutta, N.K., Pinn, M.L., and Karakousis, P.C. (2014). Reduced emergence of isoniazid resistance with concurrent use of thioridazine against acute murine tuberculosis. Antimicrob. Agents Chemother. 58 4048-4053. doi: 10.1128/AAC.02981-14

Dutta, N. K., Annadurai, S., Mazumdar, K., Dastidar, S. G., Kristiansen, J. E., Molnar, J., et al. (2007). Potential management of resistant microbial infections with a novel non-antibiotic: the anti-inflammatory drug diclofenac sodium. Int. J. Antimicrob. Agents 30, 242-249. doi: 10.1016/j.ijantimicag.2007.04.018

Dutta, N. K., Bruiners, N., Pinn, M. L., Zimmerman, M. D., Prideaux, B., Dartois, V., et al. (2016). Statin adjunctive therapy shortens the duration of TB treatment in mice. J. Antimicrob. Chemother. 71, 1570-1577. doi: 10.1093/jac/dkw014

Dutta, N. K., Mehra, S., and Kaushal, D. (2010). A Mycobacterium tuberculosis sigma factor network responds to cell-envelope damage by the promising anti-mycobacterial thioridazine. PLOS ONE 5:e10069. doi: 10.1371/journal.pone.0010069

Emmerich, R., and Löw, O. (1899). Bakteriolytische enzyme als Ursache der erworbenen Immunität und die Heilung von Infectionskrankheiten durch dieselben. Z. Hyg. 31, 1-6510. doi: 10.1007/BF02206499

Fleming, A. (1929). On antibacterial action of culture of Penicillium, with special reference to their use in isolation of B. influenzae. Br. J. Exp. Pathol. 10, 226-236. constantly growing global threat to public health worldwide and has been declared as a thrust area by World Health Organization (WHO). AMR is mediated via various mechanisms such as enzymatic degradation of drugs, alteration of antimicrobial targets, efflux of drugs, alteration of microbial membrane permeability, formation of biofilms, and persister cell states. Most of the AMR resistance genes (ARG) are disseminated via horizontal gene transfer mediated by genetic elements like plasmids, transposons, bacteriophages, and other genetic elements (Thombre et al., 2016). One of the challenges of AMR is annihilating the spread and prevalence of ARGs in the environmental resistome via plasmids. Future strategies and new lines of research need to be undertaken using conjugation inhibitors, plasmid incompatibility systems, and CRISPR/Casbased approaches to tackle the incredibly profound multidrug resistant bacteria (Buckner et al., 2018).

\section{AUTHOR CONTRIBUTIONS}

All authors listed have made a substantial, direct and intellectual contribution to the work, and approved it for publication.

\section{ACKNOWLEDGMENTS}

We would like to thank the contributing authors for submission of their papers and reviewers for their valuable time. The Editorial guidance and suggestions of Dr. Rustam Aminov for handling this special issue is highly appreciated. RT thanks the Principal, Modern College, Shivajinagar, Pune, for providing necessary facilities.

Frank, D. J., Horne, D. J., Dutta, N. K., Shaku, M. T., Madensein, R., Hawn, T.R., et al. (2019). Remembering the host in tuberculosis drug development. J. Infect. Dis. 219, 1518-1524. doi: 10.1093/infdis/jiy712

Mazumdar, K., Asok Kumar, K., and Dutta, N. K. (2010). Potential role of the cardiovascular non-antibiotic (helper compound) amlodipine in the treatment of microbial infections: scope and hope for the future. Int. J. Antimicrob. Agents 36, 295-302. doi: 10.1016/j.ijantimicag.2010.0 5.003

Mazumdar, K., Dastidar, S. G., Park, J. H., and Dutta, N. K. (2009). The anti-inflammatory non-antibiotic helper compound diclofenac: an antibacterial drug target. Eur. J. Clin. Microbiol. Infect. Dis. 28, 881-891. doi: 10.1007/s10096-009-0739-z

Thombre, R. S., Shinde, V., Thaiparambil, E., Zende, S., and Mehta, S. (2016) Antimicrobial activity and mechanism of inhibition of silver nanoparticles against extreme halophilic archaea. Front. Microbiol. 7:1424. doi: $10.3389 /$ fmicb. 2016.01424

Conflict of Interest: The authors declare that the research was conducted in the absence of any commercial or financial relationships that could be construed as a potential conflict of interest.

Copyright (C) 2019 Thombre, Jangid, Shukla and Dutta. This is an open-access article distributed under the terms of the Creative Commons Attribution License (CC BY). The use, distribution or reproduction in other forums is permitted, provided the original author(s) and the copyright owner(s) are credited and that the original publication in this journal is cited, in accordance with accepted academic practice. No use, distribution or reproduction is permitted which does not comply with these terms. 